\title{
Systolic anterior motion of the mitral valve after aortic valve replacement
}

\author{
John F. Zaki, MDª Travis Markham, MDª, Warren Choi, MDª, Ovidiu Moise, MDa , Muaz Aijazi, MD @ ${ }^{\mathrm{b}}$, \\ and Roy Sheinbaum, MDa \\ ${ }^{a}$ Department of Anesthesiology, University of Texas Health Science Center at Houston, Houston, Texas; buniversity of Texas Health Science Center at \\ Houston, Houston, Texas
}

\section{ABSTRACT}

We present a case of severe systolic anterior motion developing intraoperatively after aortic valve replacement for aortic valve stenosis.

KEYWORDS aortic valve replacement; cardiopulmonary bypass; mitral valve; systolic anterior motion; transthoracic echocardiogram

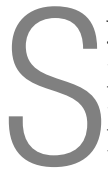
ystolic anterior motion (SAM) of the mitral valve is a paradoxical motion of the anterior, and occasionally posterior, mitral valve leaflet toward the ventricular septum during ventricular systole. Although SAM is well reported in cases of hypertrophic cardiomyopathy, there are relatively fewer cases that describe severe SAM in association with aortic valve replacement (AVR) for aortic valve stenosis. ${ }^{1-3}$ The authors believe that this report adds insight into identification and management of an underrecognized cause of hemodynamic instability after AVR. ${ }^{1-3}$

\section{CASE PRESENTATION}

A 62-year-old, 163-cm, 65-kg woman with previous hypertension and hyperlipidemia presented for AVR following diagnosis with severe aortic valve stenosis. The diagnosis was made after the patient reported increased exercise intolerance, chest pain, and syncope. Her preoperative transthoracic echocardiogram revealed an ejection fraction of $60 \%$, aortic valve area of $0.5 \mathrm{~cm}^{2}$, mean gradient of $59 \mathrm{~mm} \mathrm{Hg}$, and left ventricular outflow tract area of $1.7 \mathrm{~cm}$.

General anesthesia was induced with midazolam $(3 \mathrm{mg})$, fentanyl $(50 \mu \mathrm{g})$, and propofol $(30 \mathrm{mg})$. Transient hypertension was treated with esmolol $(30 \mathrm{mg})$. Maintenance of general anesthesia was achieved by a combination of fentanyl, midazolam, and sevoflurane. Intraoperative transesophageal echocardiography showed a heavily calcified trileaflet aortic valve with a peak velocity of $4.2 \mathrm{~m} / \mathrm{s}$, mean gradient of $62 \mathrm{~mm} \mathrm{Hg}$, and preserved left ventricular systolic function. The aortic valve was replaced with a \#23 St. Jude Trifecta Tissue valve (St. Jude Medical) and then secured using COR-KNOT (LSI Solutions). A 4-0 Prolene suture was used to close the aorta.
Hemodynamic instability was encountered while weaning from cardiopulmonary bypass. Systolic anterior motion (SAM) and subsequent left ventricular outlet obstruction, which had not been evident prior to AVR, were subsequently identified on transesophageal echocardiography. The remainder of the exam showed a normal functioning bioprosthetic valve with an aortic valve area of $3.2 \mathrm{~cm}^{2}$. The left ventricular outflow pressure gradient was $65 \mathrm{~mm} \mathrm{Hg}$, and the outflow diameter was about $1.2 \mathrm{~cm}$ during observed SAM. Additionally, severe mitral regurgitation with SAM was clearly identifiable (Figure 1). M-mode confirmed the diagnosis with coarse fluttering of the aortic valve cusps. Unstable hemodynamics persisted as the patient became tachycardic with a heart rate of about 120 beats per minute and systolic blood pressure $<80 \mathrm{~mm} \mathrm{Hg}$. Full cardiopulmonary bypass was continued while the decision was made to attempt to medically manage the situation with volume loading and beta-blockade. An additional $50 \mathrm{mg}$ of esmolol was administered to temporize the increased contractility that was exacerbating the SAM. Aggressive volume loading was simultaneously initiated to increase the left ventricular end diastolic volume. This medical management during continued bypass for the outflow obstruction led to stabilization of her hemodynamics and improvement to a minimal amount of SAM. She was then successfully weaned off cardiopulmonary bypass.

Postoperative echocardiogram revealed no left ventricular outflow tract obstruction. The patient was transferred immediately to the cardiovascular intensive care unit and extubated on the first postoperative day. She was started on metoprolol postoperatively. Her stay was complicated by new-onset atrial fibrillation with rapid ventricular response. It eventually

Corresponding author: Muaz Aijazi, MD, University of Texas Health Science Center at Houston, 7000 Fannin Street, Suite 1200, Houston, TX 77030 (e-mail: muazajz@gmail.com)

Received December 5, 2017; Revised December 26, 2017; Accepted December 28, 2017. 


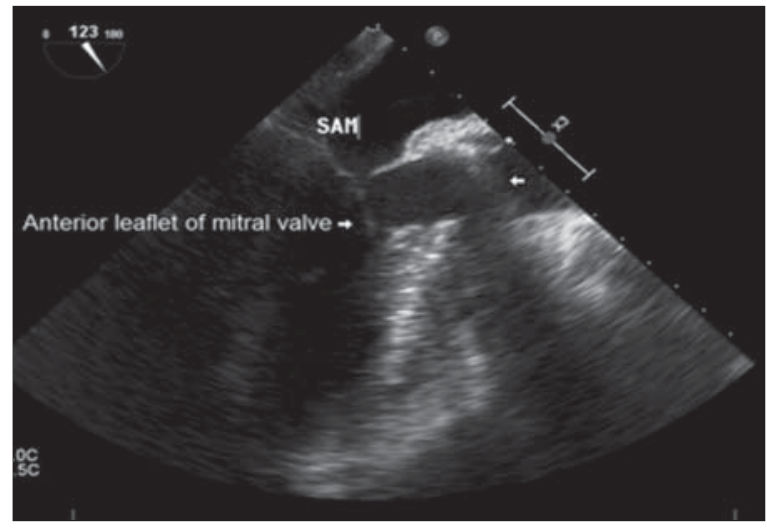

Figure 1. Transesophageal echocardiographic still image showing the anterior mitral leaflet touching the intraventricular septum during systole, diagnosed as systolic anterior motion of the mitral valve.

resolved after a course of amiodarone and continued betablockade. She was discharged home on postoperative day 10 .

\section{DISCUSSION}

SAM following AVR may be an underrecognized cause of hemodynamic instability in the perioperative period, with some instances of hemodynamically significant SAM occurring days to months after the initial procedure. This highlights the importance of pre- and intraoperative echocardiographic assessment, as well as a high index of suspicion intraoperatively during the weaning process for these patients.

To identify factors predisposing to SAM, Xu et al conducted a case series with 48 patients who underwent AVR for severe aortic stenosis and suggested that increased gradients of left ventricular outflow are the main cause of SAM. ${ }^{4}$ Sukernik et al then stated that interventricular septum bulging and concentric left ventricular hypertrophy secondary to longstanding hypertension were possible predisposing factors for SAM in patients after AVR. ${ }^{5}$ The presence of a hyperdynamic state, relatively small left ventricular cavity, narrow outflow tract, or elongated mitral valve anterior leaflet were also identified as potential risk factors. ${ }^{4,5}$
Our patient had longstanding hypertension leading to concentric left ventricular hypertrophy. She had an enlarged interventricular septum as well as an increased mean left ventricular outflow gradient. Moreover, coming off cardiopulmonary bypass, she was hypovolemic, which led to a hyperdynamic state. We believe that this report lends further credence to the suggestions put forth by prior investigations into SAM, allowing for use of narrower criteria when deciding which patients to observe more closely after AVR. Close observation of select high-risk patients allows for rapid detection of SAM and potential avoidance of further surgical intervention.

\section{Funding}

Funding was provided by the University of Texas Health Science Center at Houston Department of Anesthesiology, Houston, Texas, and the Memorial Hermann Heart \& Vascular Institute, Houston, Texas. The authors have no conflicts of interest to disclose.

\section{ORCID}

Muaz Aijazi (iD) http://orcid.org/0000-0003-1629-8895

1. Routledge T, Nashef S. Severe mitral systolic anterior motion complicating aortic valve replacement. Interact Cardiovasc Thorac Surg. 2005;4(5):486-487.

2. Cutrone F, Coyle J, Novoa R, Stewart R, Currie P. Severe dynamic left ventricular outflow tract obstruction following aortic valve replacement diagnosed by intraoperative echocardiography. Anesthesiology. 1990;72(3):563-566.

3. Kerut EK, Hanawalt C, Dearstine M, Frank R, Everson C. Mitral systolic anterior motion (SAM) with dynamic left ventricular outflow obstruction following aortic valve replacement. Echocardiography. 2007;24(6):658660.

4. Xu J, Wen J, Shu L, Liu C, Zhang J, Zhao W. Mechanism and correlated factors of SAM phenomenon after aortic valve replacement. J Huazhong Univ Sci Technolog Med Sci. 2007;27(1):72-74.

5. Sukernik MR, Sumner AD, Pae WE. Systolic anterior motion of the mitral valve after aortic valve replacement for aortic insufficiency. J Cardiothor Vasc Anesth. 2007;21(4):574-576. 